\title{
Radial Distribution Characteristics of Microstructure and Mechanical Properties of Ti-6Al-4V Butt Joint by Rotary Friction Welding
}

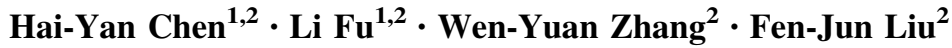

Received: 16 March 2015/Revised: 11 September 2015/Published online: 15 October 2015

(C) The Chinese Society for Metals and Springer-Verlag Berlin Heidelberg 2015

\begin{abstract}
Ti-6Al-4V rods were butt-welded by rotary friction welding in this study. Additionally, the radial differences in microstructure and mechanical property of joints were investigated by hierarchy slicing method. The results displayed that the width of weld zone and heat-affected zone of joints became wider along radial direction. Meanwhile, the tensile strength of joints decreased gradually along the radial direction. According to the theoretical analysis, the temperature gradient and inhomogeneous forging pressure leaded to the radial differences. Through K-type thermocouples, the actual temperatures at different locations were measured, and the results were consistent with the theoretical analysis. Theoretically, the radial differences of rotary friction welding joint are an inherent phenomenon; thus, the size of weldment should be limited strictly below the corresponding critical size. In order to prevent radial differences from enlarging, the welding surface profile of weldment can be processed into oval shape, and a larger forging pressure can be used within the scope of the joint deformation allowed according to causes for radial differences.
\end{abstract}

KEY WORDS: Titanium alloys; Friction welding; Microstructure; Mechanical property

\section{Introduction}

Rotary friction welding, as a solid-state welding method, is widely used in aeronautic, automotive, and mechanical manufacture industry $[1,2]$. During the friction stage, the contact interfaces of two components are compelled to rub against each other, leading to the heat production in a sufficiently narrow interfacial layer. Once enough frictional heat is generated, the contact interfaces are softened and forged together. Generally, a high-quality and even full-

Available online at http://link.springer.com/journal/40195

$\mathrm{Li} \mathrm{Fu}$

fuli@nwpu.edu.cn

1 State Key Laboratory of Solidification Processing, Northwestern Polytechnical University, Xi'an 710072, China

2 Shaanxi Key Laboratory of Friction Welding Technologies, Xi'an 710072, China strength joint can be obtained by friction welding method [3]. Nevertheless, fracture failure of joint usually occurs in the seam even though the strength of joint is as high as that of the base metal $[4,5]$. The fracture failure is attributed to the existence of weak areas in seam [6]. Based on the theoretical analysis and experimental study, it is found that both the microstructure and mechanical properties of joint along the radial direction have some obvious and regular differences. However, few investigations on the differences and laws are reported.

To date, a lot of materials, such as steels, copper, aluminum alloys, and titanium alloys [7-10], have been joined successfully by friction welding. For titanium alloys, it is easier to obtain a relatively homogeneous joint by linear friction welding [11] or friction stir welding [10] rather than rotary friction welding [12]. The differences of joints welded by the three friction welding methods mainly derive from the differences of heat distribution, pressure distribution, and plastic flow behavior of interface material during the welding [13]. At present, the linear friction 
welding of titanium alloys is more mature, while the friction stir welding and the rotary friction welding have some issues. In particular, the radial differences in mechanical properties of titanium alloys joints hamper the application of rotary friction welding method. Although the whole joint meets the technical requirements of conventional fields, local joint may be lower than the application standard owing to the principle of friction welding and even lead to the overall failure of joint [14]. Therefore, it is a critical issue to find the weak areas of joint and analyze the cause of the defects. According to the welding principle and process, the frictional heat and forging pressure play a main role for the satisfied microstructure and excellent mechanical properties of joint. However, the heat and pressure in interfacial layer are not uniform, which leads to the differences in the microstructure and mechanical properties of joint along the radial direction. The radial differences have important significance for the further understanding of friction welding principle and process optimization method. Through investigating the radial differences and analyzing the related causes, it can guide us to put forward new theory and technique to reduce the radial differences in microstructure and mechanical property of joints. Therefore, the laws and causes of radial differences are still worth studying and exploring.

In the present study, $\mathrm{Ti}-6 \mathrm{Al}-4 \mathrm{~V}$ rods were butt-welded by rotary friction welding. Subsequently, the microstructure and mechanical property of joint along the radial direction were investigated by hierarchy slicing method. In order to explore the cause of radial differences, the temperature at feature points in interfacial layer was measured by thermocouples. Finally, the influence of welding mechanism on the microstructure and quality of joint along the radial direction was deep analyzed, which provides a theoretical guidance for the process optimization of rotary friction welding.

\section{Experimental}

The base materials used in this study are commercial hotrolled Ti-6Al-4V cylindrical rods of $25 \mathrm{~mm}$ diameter and $120 \mathrm{~mm}$ length. All surfaces for welding were polished by $\mathrm{SiC}$ papers up to grit 1000 and degreased with acetone. The friction welding experiments were performed on the continuous drive friction welding machine (C200-1). The welding process parameters are listed in Table 1.

The macro-morphology and microstructure of the joints after welding were observed by optical microscopy (PMG3 ). In order to survey the influences of welding process on the mechanical property of joint along the radial direction, the joint quality was assessed by hierarchy slicing method. The joints were sliced by means of electrical discharge machining and machined to the dimensions of tensile specimen as shown in Fig. 1. The tensile specimens were polished to avoid the surface stress concentration. The tensile tests were carried out at a displacement speed of $0.5 \mathrm{~mm} / \mathrm{min}$ in an Instron 3365 universal test machine at room temperature. After tensile tests, the fracture surfaces were examined by scanning electron microscopy (SEM, JC-5700).

The temperatures were measured at four feature locations within the stationary specimen during the welding process using K-type thermocouples. Holes of $0.8 \mathrm{~mm}$ diameter were drilled at different locations within the stationary specimen, and the distribution of the holes is shown in Fig. 2. The thermocouples were beaded at the tip and stuck at the measuring points with glue. An industrial control computer was employed to collect the related data.

\section{Results}

The joint quality, welding precision and mechanical strength, can be reflected by the shapes of weld zone, heataffected zone, and flash in some degree. Generally, the more the volume of flash forms, the higher the mechanical strength of joint becomes. On the other hand, with increasing volume of flash, the axial shortening increases after forging stage. Therefore, it is a key issue to keeping a balance between mechanical strength and axial shortening of joints.

Figure 3 shows the optical images of joints welded under different welding parameters. When the rotational speed and friction pressure were constant, the volume of flash increased with friction time from 2 to $4 \mathrm{~s}$, but the increment was not obvious from 4 to $6 \mathrm{~s}$, as shown in Fig. 3a-c. The width of weld zone and heat-affected zone decreased firstly with the friction time from 2 to $4 \mathrm{~s}$ and then increased when the friction time was extended to $6 \mathrm{~s}$. The tendency is attributed to the size of softened zone resulting from the differences of frictional heat. With the extending friction time from 2 to $4 \mathrm{~s}$, the softened zone widens, which leads to the increase in the flash volume and the reduction in the width of heat-affected zone after the forging process. However, the softened zone has no obvious change in width due to the reduction in friction coefficient when the friction time is extended to $6 \mathrm{~s}$. The extension of friction time just leads to the increase in the width of weld zone and heat-affected zone owing to heat conduction. When the friction pressure and friction time were chosen as $46 \mathrm{MPa}$ and $4 \mathrm{~s}$, the volume of flash enlarged with the increase in rotational speed from 1500 to 2500 r/min, as shown in Fig. 3d-f. From Fig. 3, it can be seen that the weld zone and heat-affected zone of the center 
Table 1 Welding process parameters for rotary friction welding

\begin{tabular}{llllll}
\hline Sample & Rotational speed $(\mathrm{r} / \mathrm{min})$ & Friction time $(\mathrm{s})$ & Friction pressure $(\mathrm{MPa})$ & Forging pressure $(\mathrm{MPa})$ & Forging time $(\mathrm{s})$ \\
\hline R1 & 2500 & 2 & 28 & 92 & 2 \\
R2 & 2500 & 4 & 28 & 92 & 2 \\
R3 & 2500 & 6 & 28 & 92 & 2 \\
F1 & 1500 & 4 & 46 & 92 & 2 \\
F2 & 2000 & 4 & 46 & 92 & 2 \\
F3 & 2500 & 4 & 46 & 92 & 2 \\
\hline
\end{tabular}

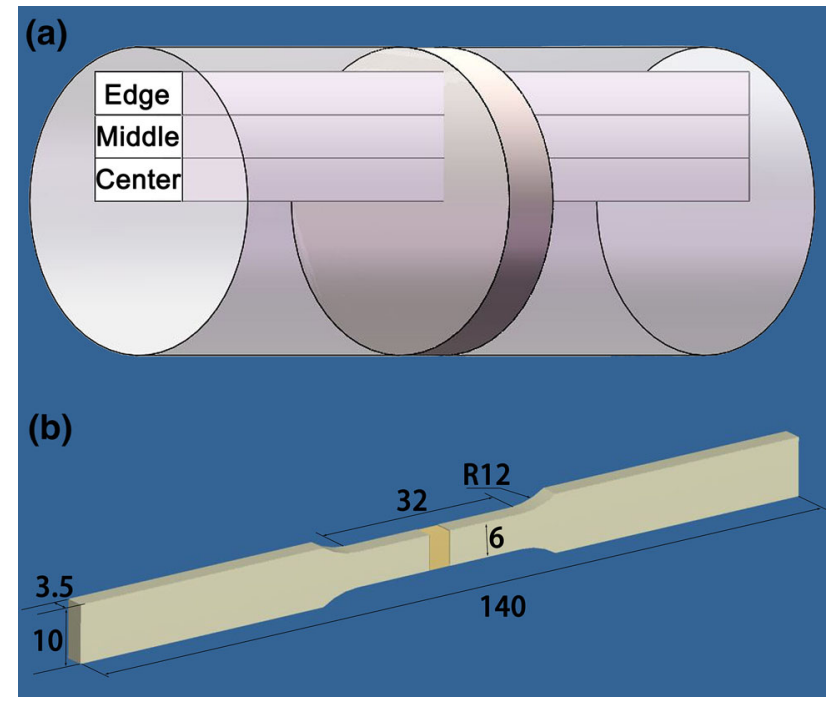

Fig. 1 Schematic diagrams of slicing positions a and dimensions of tensile specimens (unit: $\mathrm{mm}$ ) b

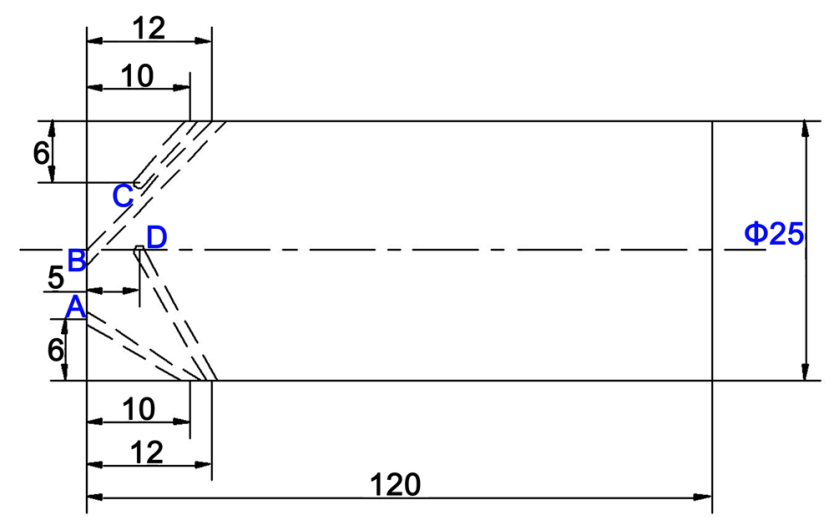

Fig. 2 Locations of thermocouples $A, B, C, D$ in fixed side (unit: $\mathrm{mm}$ )

were the narrowest, while those of the edge were the widest.

For Ti-6Al-4V alloy, the typical microstructure consists of a combination of elongated $\alpha$ grains and $\beta$ matrix. Figure 4 shows the microstructures along the radial direction of joint R2. The weld zone and heat-affected zone of joints take a shape of the letter $\mathrm{X}$. The width of the weld zone and heat-affected zone at the center of joint was the narrowest, as shown in Figs. $3 \mathrm{~b}$ and $4 \mathrm{a}$. The causes were attributed to the weaker mechanical friction and the less frictional heat during the welding. Form Fig. $4 \mathrm{~b}$, it can be found that the microstructure of weld zone is primary $\alpha$ particles and secondary $\alpha$ lamellar phases in $\beta$ matrix at the center of joint. Due to the low temperature, no obvious phase transformation is found in heat-affected zone at the center of joint, as shown in Fig. 4c. Moreover, the flow line of mechanical deformation is also not obvious in heat-affected zone. With increasing distance from the center of joint, the weld zone and heat-affected zone widen gradually, as shown in Fig. 4d, g. It is attributed to the increase in thermoplastic zone resulting from the addition of linear friction speed along the radial direction. Compared with the grain size of weld zone at the center of joint, it can be found from Fig. $4 \mathrm{e}, \mathrm{h}$ that the recrystallized grain size of weld zone increases along radial direction due to the rise of temperature. From Fig. 4c, f, i, it can be found that the flow line of mechanical deformation of the heat-affected zone becomes more and more obvious, which is consistent with the linear velocity theory.

Figure 5 shows the tensile strength of the slices under different process parameters. With increasing friction time, the tensile strength of the center slices gradually decreased, while the middle and peripheral slices increased and then decreased. In addition, the tensile strength of the center slices was significantly higher than that of the peripheral slices, as shown in Fig. 5a. When the rotational speed increased from 1500 to $2500 \mathrm{r} / \mathrm{min}$, the tensile strength of the slices at the same position showed a tendency to increase. For the effect of friction pressure, it can be seen from Fig. $5 \mathrm{c}$ that the tensile strength of slices at different position had no obvious differences when the friction pressure was $46 \mathrm{MPa}$. However, the tensile strength of the peripheral slices was significantly lower than that of the center and middle slices. 

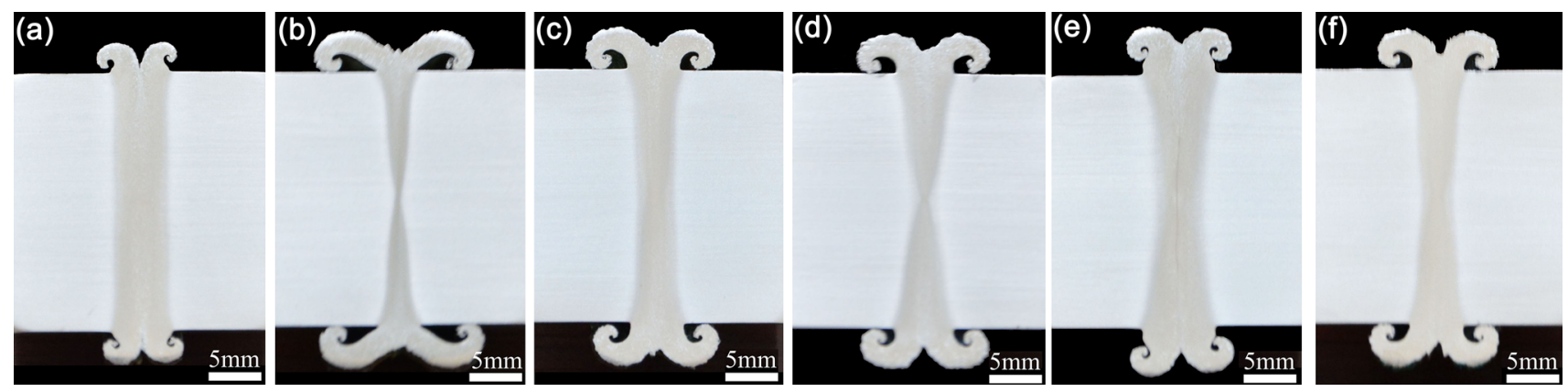

Fig. 3 Optical images of joints welded under different welding parameters: a sample R1, b sample R2, c sample R3, d sample F1, e sample F2, f sample F3
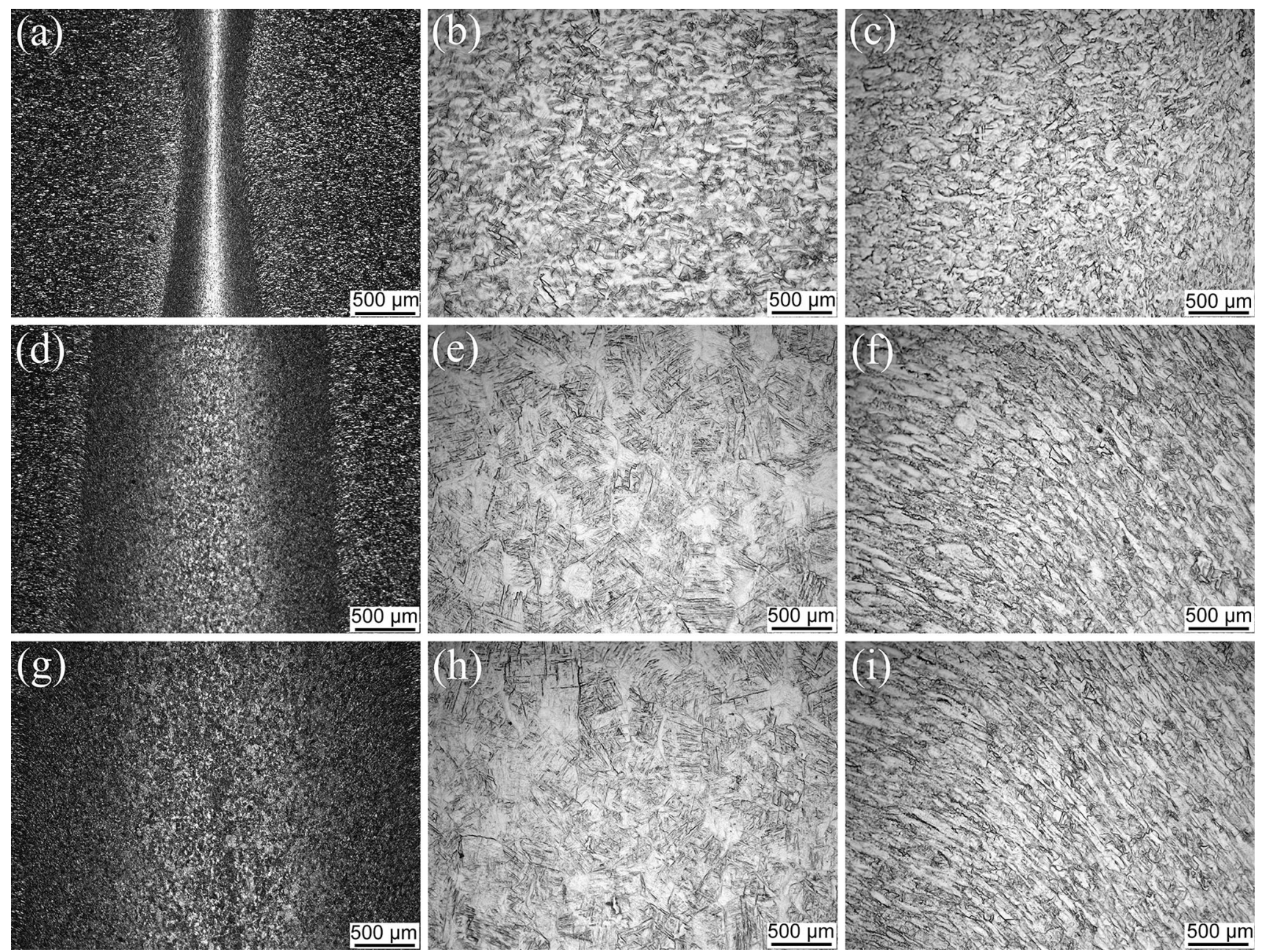

Fig. 4 Optical micrographs at different positions of joint R2: a overall weld at the center of joint, $\mathbf{b}$ weld zone at the center of joint, $\mathbf{c}$ heataffected zone at the center of joint, $\mathbf{d}$ overall weld at the middle of joint, $\mathbf{e}$ weld zone at the middle of joint, $\mathbf{f}$ heat-affected zone at the middle of joint, $\mathbf{g}$ overall weld at the edge of joint, $\mathbf{h}$ weld zone at the edge of joint, $\mathbf{i}$ heat-affected zone at the edge of joint

Figure 6 shows the images of slices after tensile tests. The weld seam is located in the middle of the tensile specimens. From Fig. 6, it can be seen that the peripheral tensile specimen had no obvious plastic deformation and fractures at the original weld seam during tensile test, indicating that the quality of weld seam was worse than base metal. Unlike the peripheral slice, the apparent necking can be found at the middle and center slices and 
(a)

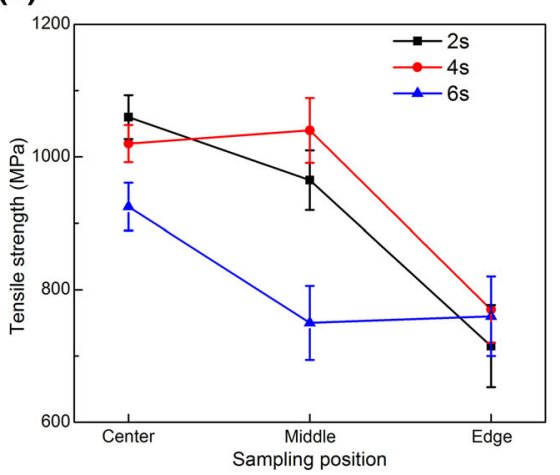

(b)

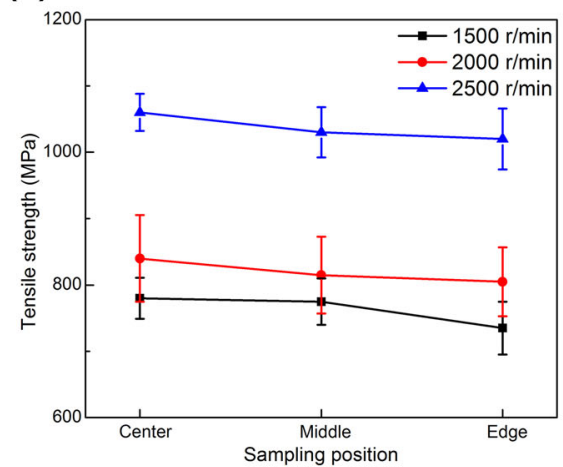

(c)

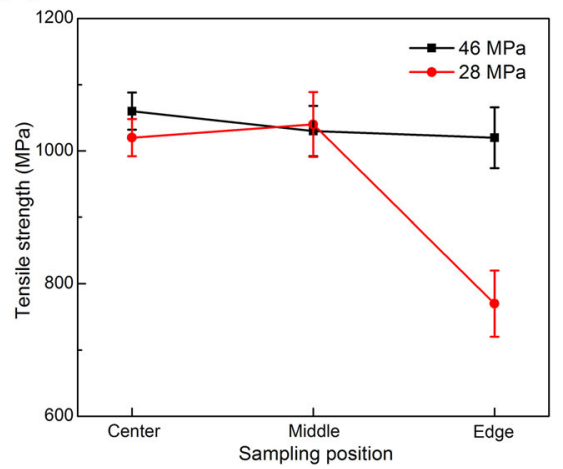

Fig. 5 Tensile strengths of the slices of joints welded under the different friction time a, the different rotational speeds $\mathbf{b}$, and the different friction pressures $\mathbf{c}$

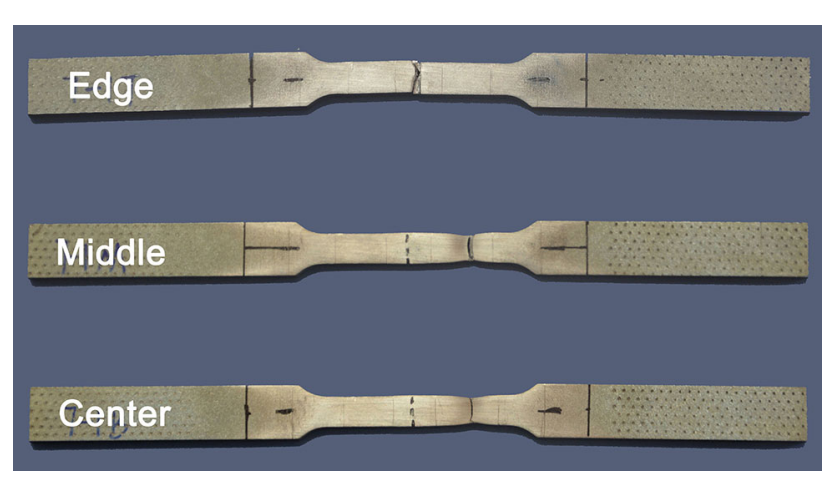

Fig. 6 Macro-characterization of slices of joint welded with process parameters R2 after tensile tests

the fracture occurred in the base metal. The site and mode of fracture illustrated that the welding quality near the center was superior to that far from the center.

Figure 7 shows the stress-strain curves of the slices of joints welded under different process parameters. In the stress-strain curves of the slices of joint welded under the friction pressure of $28 \mathrm{MPa}$, both the fracture stress and the elongation of the peripheral slice are lower than those of the center and middle slices as shown in Fig. 7a. When the friction pressure rose to $46 \mathrm{MPa}$, the fracture stress and the elongation of all slices were almost same, suggesting that the differences in joint quality along the radial direction are reduced with increasing friction pressure.

Temperature variations of some feature positions during the friction welding were measured experimentally. Figure 8 shows the temperature-time curves of the feature positions during the rotary friction welding. There are two important laws that can be found from the curves. In the axial direction, the temperature near the interface was higher than that far from the interface because of the frictional heat produced in the interface. In the radial direction, the temperature at the center was less than that at the middle-radius because heat production was linearly proportional to the distance from the centerline. Under the same rotary speed, the longer the friction time, the higher (a)

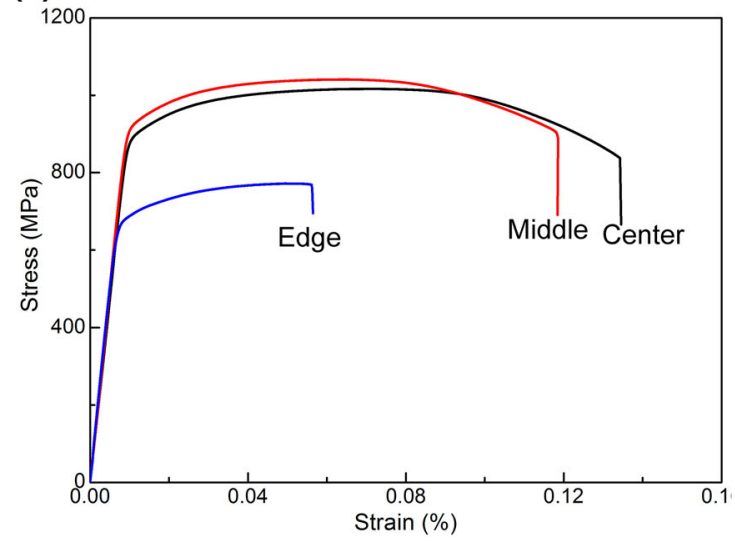

(b)

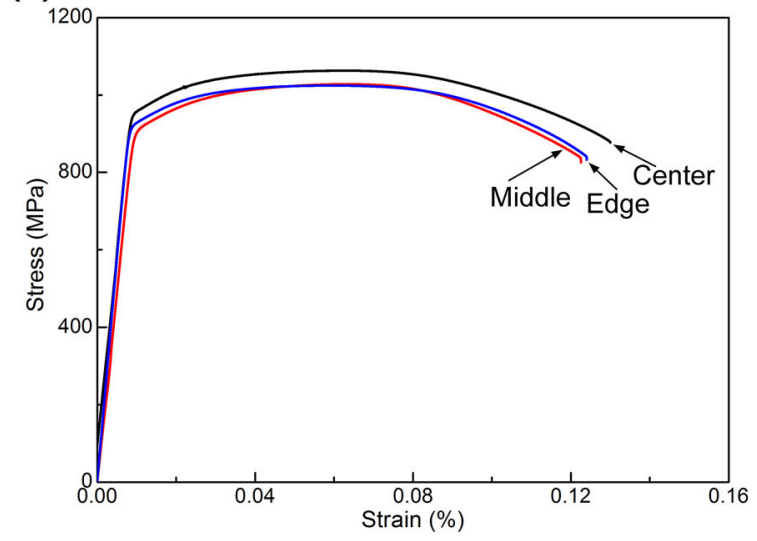

Fig. 7 Stress-strain curves of the slices of joints welded under different process parameters: a sample R2, b sample F3 
(a)

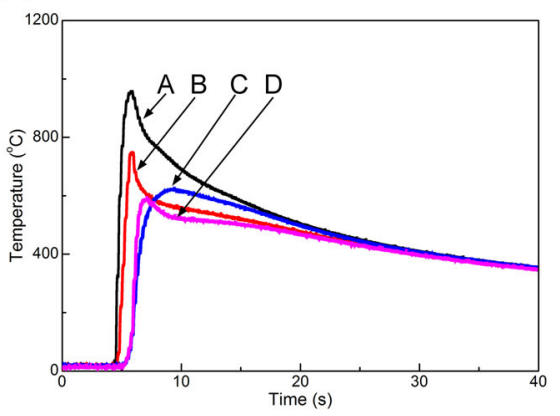

(b)

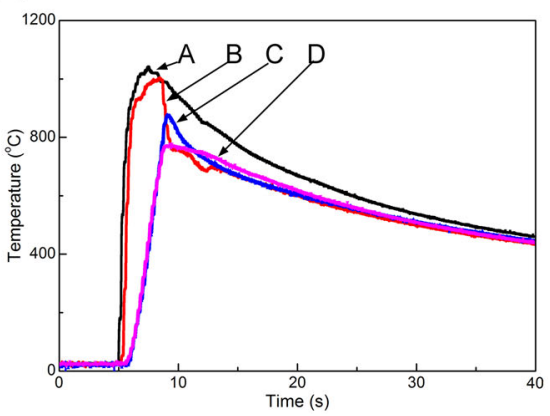

(c)

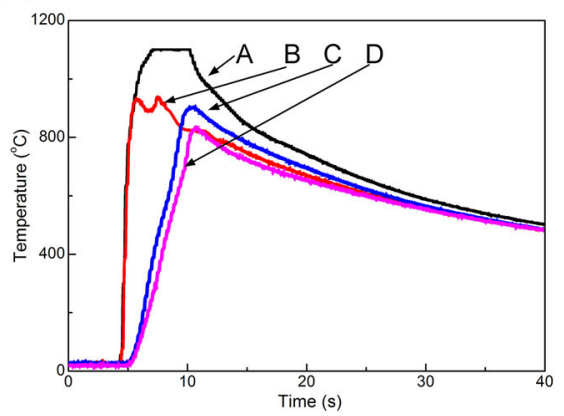

Fig. 8 Temperature-time curves of different measured positions during the friction welding: a sample R1, b sample R2, c sample R3

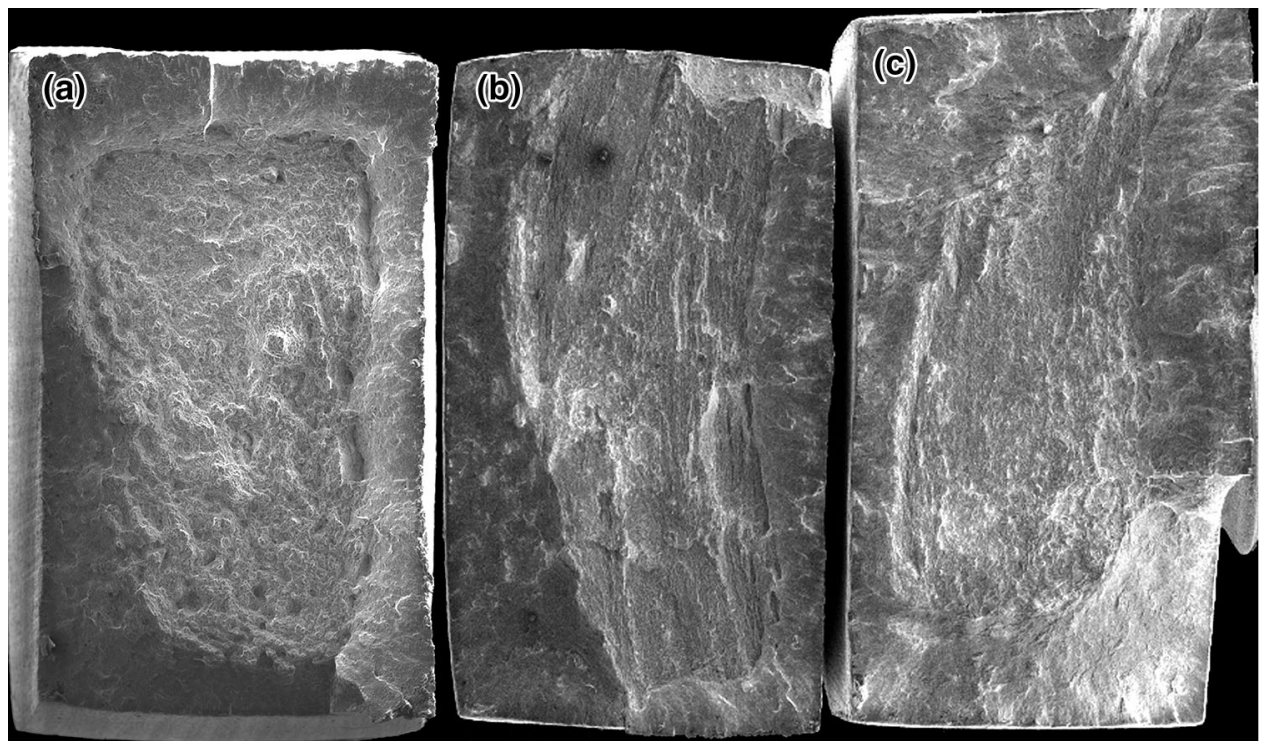

Fig. 9 SEM images of the fracture of joint R2: a center, $\mathbf{b}$ middle, $\mathbf{c}$ edge

the peak temperature, as shown in Fig. 8a-c. Owing to the extrusion of the high-temperature plastic material during the forging stage, the temperature at the center sharply decreases, resulting in a low cooling rate in the edge of interface.

In order to investigate the fracture mode, fracture analysis was performed by SEM. SEM micrographs of fractures are shown in Fig. 9. From Fig. 9, it can be seen that the overall morphology of all the three slices presents the ductile failure mechanism. The fracture surface of the middle slice has big and homogeneous dimples, while the fracture surface of the center slice has the smaller fraction of fiber region. Compared with the center and middle slices, the dimples in the fracture surface of the edge slice are small and shallow. According to the fracture morphology, it can be concluded that the center and middle slices have better toughness and higher strength, while the edge slice possesses poor tough and low strength.

\section{Discussion}

From the results above, it can be found that there are obvious differences in the microstructure and mechanical property of joints along the radial direction. According to the welding process, the temperature and plastic deformation in the interface are two major factors influencing the microstructure [10]. As for the radial differences in mechanical property of joints, the differences in the temperature and forging pressure are considered to be the major influential factors [15]. Therefore, it is crucial for understanding the radial differences to analyze heat generation, plastic deformation, and forging pressure during the welding.

According to the heat generation mechanism, the heat generated by friction between the weldments can be given by $[15,16]$

$q=\mu \omega p r$ 
where $q$ is the heat generated by friction and $\mu, \omega, p$, and $r$ are the friction coefficient, angular velocity, contact pressure, and inner radius, respectively.

For the rotary friction welding of titanium alloy, it can be deduced from Eq. (1) that the heat generation is linearly proportional to the distance from the centerline. Thus, theoretically, the highest temperature gradually increases along the radial direction during the friction stage. The experimental results also revealed that the temperature at the center was less than that at the middle, which is in good agreement with heat generation theory $[11,16]$. On the other hand, the highest temperature gradually decreased along the axial direction due to the convection cooling effect [9], which is consistent with the practical results in Fig. 8. For the friction welding of TC4, the purpose of friction process was to achieve the temperature needed for the welding. When the temperature was lower than the required value (Fig. 8a), it is difficult to obtain a satisfactory joint (joint R1) because of the poor plastic deformation of interfacial region. When the temperature was much higher than the required value (Fig. 8c), the mechanical property of joint (joint R3) was also unsatisfactory due to the coarse-grain microstructure. When the temperature was close to the required value, the tensile strength of joint (joint R2) was the highest compared with joint R1 and R3.

As for the radial differences in mechanical property of joints, the forging pressure is an important influential factor besides the temperature. Moreover, the forging pressure at the interface also exhibits axial differences owing to the change of yielding stress. For TC4 alloy, the yielding stress is related to the temperature and reduces with the increase in the temperature [17]. Thus, the yielding stress of center region is the highest during the friction stage and forging stage. It means that the pressure loaded in the center region of joint is higher than that in the middle or edge in order to resist the forging pressure. According to published researches [15], von Mises stress decreases along the radial direction at the interface during the forging process. In general, the higher the forging pressure, the higher the tensile strength of joint.

Based on the mechanism of friction welding, the difference in linear velocity during the friction process leads to the difference in temperature, which causes the difference in yielding stress and forging pressure along radial direction. The above reasons resulted in the radial differences in microstructure and mechanical property of rotary friction joint. Moreover, the radial differences will become more obvious with the increase in the joint radius. Therefore, the size of weldment welded by rotary friction welding could not be infinite, but should be limited strictly below the corresponding critical size. Owing to the limitation, the application of rotary friction welding method mainly concentrates on the welding of fine round bars or pipe at present $[7,12]$. According to the causes for radial differences, the reduction in temperature gradient can be considered by designing a reasonable shape of friction surface. In order to reduce the temperature in the periphery, the shape of friction surface profile of weldment can be processed into oval shape, ensuring that the friction behavior in the center happens before the periphery. Meanwhile, in order to ensure the enough forging pressure in the periphery, the larger forging pressure should be used within the scope of the joint deformation allowed.

\section{Conclusions}

(1) With the extension of friction time, the tensile strength of the center slices kept decreasing, while that of the middle and peripheral slices increased firstly and then decreased. With the increase in rotational speed, the tensile strength of all slices increased. The optimal processing parameters are as follows: Rotational speed is $2500 \mathrm{r} / \mathrm{min}$ and friction time is $4 \mathrm{~s}$.

(2) Along the radial direction, the weld zone and heataffected zone became wider, and the tensile strength presented a downtrend basically. The radial differences in microstructure and mechanical property of joint will become more obvious with the increase in the joint radius theoretically.

(3) The radial differences were attributed to the temperature gradient and nonuniform forging pressure. The difference in linear velocity during the friction stage leaded to the temperature gradient, thereby causing differences in yielding stress and von Mises stress.

Acknowledgments This work was financially supported by the National Natural Science Foundation of China (No. 51405390), Project of Key areas of innovation team in Shaanxi Province (No. 2014KCT12), Northwestern Polytechnical University Foundation for Fundamental Research (No. 3102014JCQ01017), the fund of the State Key Laboratory of Solidification Processing in NWPU (No. 113-QP-2014), Natural Science Foundation of Shaanxi Province (No. 2014JM2-5083), and the Program of Introducing Talents of Discipline to Universities (No. B08040).

\section{References}

[1] D. Schmicker, P.O. Persson, J. Strackeljan, J. Comput. Phys. 270, 478 (2014)

[2] R. Winiczenko, M. Kaczorowski, Mater. Des. 34, 444 (2012)

[3] P.D. Sketchley, P.L. Threadgill, I.G. Wright, Mater. Sci. Eng. A 329-331, 756 (2002)

[4] A. Ambroziak, J. Alloys Compd. 506, 761 (2010)

[5] G.M. Reddy, P.V. Ramana, J. Mater. Process. Technol. 212, 66 (2012) 
[6] M.B. Uday, M.N.A. Fauzi, H. Zuhailawati, A.B. Ismail, Mater. Sci. Eng. A 528, 1348 (2011)

[7] R. Paventhan, P.R. Lakshminarayanan, V. Balasubramanian, Mater. Des. 32, 1888 (2011)

[8] P.M. Ajith, P. Sathiya, S. Aravindan, Acta Metall. Sin. (Engl. Lett.) 27, 995 (2014)

[9] A.Z. Sahin, B.S. Yibas, M. Ahmed, J. Nickel, J. Mater. Process. Tech. 82, 127 (1998)

[10] C. Kwietniewski, J.F. dos Santos, A.A.M. da Silva, L. Pereira, T.R. Strohaecker, A. Reguly, Mater. Sci. Eng. A 417, 49 (2006)

[11] R. Turner, J.C. Gebelin, R.M. Ward, R.C. Reed, Acta Mater. 59, $3792(2011)$
[12] P. Li, J.L. Li, M. Salman, L. Liang, J.T. Xiong, F.S. Zhang, Mater. Des. 56, 649 (2014)

[13] X.C. He, F.S. Gu, A. Ball, Prog. Mater Sci. 65, 1 (2014)

[14] P. Groche, S. Wohletz, M. Brenneis, C. Pabst, F. Resch, J. Mater. Process. Technol. 214, 1972 (2014)

[15] S.K. Singh, K. Chattopadhyay, G. Phanikumar, P. Dutta, Acta Mater. 73, 177 (2014)

[16] J.T. Xiong, J.L. Li, Y.N. Wei, F.S. Zhang, W.D. Huang, Acta Mater. 61, 1662 (2013)

[17] J.Q. Zhang, H.S. Di, H.T. Wang, K. Mao, T.J. Ma, Y. Cao, J. Mater. Sci. 47, 4000 (2012) 